\title{
Action mechanisms of transcranial direct current stimulation in Alzheimer's disease and memory loss
}

\author{
Niels Hansen* \\ Department of Neurophysiology, Ruhr University Bochum, Bochum, Germany
}

\section{Edited by:}

Andre R. Brunoni, Universidade de São Paulo, Brazil

\section{Reviewed by:}

Luiz Kobuti Ferreira, Universidade de

Sao Paulo, Brazil

Pedro Shiozawa, Santa Casa de

Misericórdia de São Paulo, Brazil

*Correspondence:

Niels Hansen, Department of Neurophysiology, Ruhr University

Bochum, Universitätsstrasse 150, MA 4/150, 44780 Bochum, Germany.

e-mail: niels.hansen@rub.de
The pharmacological treatment of Alzheimer's disease (AD) is often limited and accompanied by drug side effects. Thus alternative therapeutic strategies such as non-invasive brain stimulation are needed. Few studies have demonstrated that transcranial direct current stimulation (tDCS), a method of neuromodulation with consecutive robust excitability changes within the stimulated cortex area, is beneficial in AD. There is also evidence that tDCS enhances memory function in cognitive rehabilitation in depressive patients, Parkinson's disease, and stroke. tDCS improves working and visual recognition memory in humans and object-recognition learning in the elderly. AD's neurobiological mechanisms comprise changes in neuronal activity and the cerebral blood flow (CBF) caused by altered microvasculature, synaptic dysregulation from ß-amyloid peptide accumulation, altered neuromodulation via degenerated modulatory amine transmitter systems, altered brain oscillations, and changes in network connectivity. tDCS alters (i) neuronal activity and (ii) human CBF, (iii) has synaptic and non-synaptic after-effects (iv), can modify neurotransmitters polarity-dependently, $(\mathrm{v})$ and alter oscillatory brain activity and (vi) functional connectivity patterns in the brain. It thus is reasonable to use tDCS as a therapeutic instrument in $A D$ as it improves cognitive function in manner based on a disease mechanism. Moreover, it could prove valuable in other types of dementia. Future large-scale clinical and mechanism-oriented studies may enable us to identify its therapeutic validity in other types of demential disorders.

Keywords: Alzheimer's disease, cerebral blood flow, frontotemporal dementia, memory loss, network connectivity, neurotransmitter modulation, synaptic and non-synaptic after-effects, transcranial direct current stimulation

\section{INTRODUCTION}

As the pharmacological treatment in Alzheimer disease (AD) is limited (Bauer, 2006), alternative therapeutic approaches are worth pursuing, such as non-invasive brain stimulation with transcranial direct current.

Transcranial direct current stimulation (tDCS) is the application of weak electrical currents by saline-soaked surface sponge electrodes to different cortical areas. tDCS can polaritydependently modulate cortical excitability with prolonged aftereffects (Nitsche et al., 2005) and modify neuronal excitability by tonic de-or hyperpolarization of the resting membrane potential (Creutzfeld et al., 1962; Purpura and McMurtry, 1965). The electrode positioning is determined according to the EEG 10-20 system.

tDCS has demonstrated efficacy in improving recognition memory in $\mathrm{AD}$ (Boggio et al., 2009, 2011) and it is a useful tool in cognitive neurorehabilitation, as improvements in cognitive functions were described in patients with depression (Fregni et al., 2006), Parkinson's disease (Boggio et al., 2006) and stroke (Monti et al., 2008).

Alzheimer's disease is a progressive neurodegenerative disorder (Thies and Bleiler, 2011) presenting a decrease in acethylcholine activity resulting in cognitive impairment (Schliebs and Arendt, 2011) in many cognitive activities such as memory, language, and executive functions.
The concept of benefiting from modulating cortical excitability via $\mathrm{tDCS}$ with consecutive improvement in cognitive functions in $\mathrm{AD}$ is thus tempting. We describe tDCS application in clinical studies in patients with dementia (see Table 1) and studies on cognitive functions (see Table 2) as well as potential underlying mechanisms in this article.

\section{METHODOLOGICAL ASPECTS}

The review section about the action mechanisms of tDCS in $\mathrm{AD}$ is based on a non-systematic approach, whereas the review section on clinical studies with tDCS in AD and memory is based on a somewhat systematic approach based on the PubMed database. A literature search for original and review articles on tDCS in demential disorders was performed through December 2011 seeking clinical studies on tDCS in AD and for demential disorders, by screening the PubMed database. The keywords were used in combination with "Alzheimer disease" AND "tDCS," "dementia" AND "tDCS" as well as "memory" AND "tDCS." The studies were published between 2004 and 12/2011. The exclusion criteria of articles in the article titles searched were only "brain stimulation," "depression," only "memory" or "Alzheimer disease," or "demential disorder" without "tDCS," "motor learning," and only "tDCS" without "memory" or "Alzheimer disease" or "demential disorder." Thirty-eight papers were screened from 75 articles according to the aforementioned criteria and 33 
Table 1 | Clinical studies of tDCS in dementia.

\begin{tabular}{|c|c|c|c|c|c|c|c|c|c|}
\hline Study & Design & $n$ & Age (years) & $\begin{array}{l}\text { Disease } \\
\text { diagnosis }\end{array}$ & MMSE & Medication & Parameters & Brain target & Effect \\
\hline \multicolumn{10}{|c|}{ ALZHEIMER'S DISEASE } \\
\hline $\begin{array}{l}\text { Boggio et al. } \\
(2009)\end{array}$ & $\begin{array}{l}\text { Cross over, } \\
\text { sham } \\
\text { controlled }\end{array}$ & 10 & $79 \pm 9$ & $\begin{array}{l}\text { NINCDS, } \\
\text { ADRADA }\end{array}$ & $17 \pm 5$ & $\begin{array}{l}\text { AChEls + } \\
\text { others }\end{array}$ & $\begin{array}{l}\text { Anodal/sham, } \\
2 \mathrm{~mA}, 30 \mathrm{~min}\end{array}$ & Left DLPFC & $\begin{array}{l}\text { Improved visual } \\
\text { recognition memory } \\
\text { after atDCS }\end{array}$ \\
\hline $\begin{array}{l}\text { Boggio et al. } \\
\text { (2011) }\end{array}$ & $\begin{array}{l}\text { Sham } \\
\text { controlled }\end{array}$ & 15 & $78 \pm 7,81 \pm 10$ & $\begin{array}{l}\text { Adas-Cog, } \\
\text { VRT, VAT, } \\
\text { ADAS }\end{array}$ & $\begin{array}{l}21 \pm 3 \\
19 \pm 3\end{array}$ & No data & $\begin{array}{l}\text { Anodal, sham } \\
2 \mathrm{~mA}, 30 \mathrm{~min}\end{array}$ & TC bilateral & $\begin{array}{l}\text { Improved visual } \\
\text { recognition memory } \\
\text { after atDCS }\end{array}$ \\
\hline $\begin{array}{l}\text { Ferrucci et al. } \\
\text { (2008a) }\end{array}$ & $\begin{array}{l}\text { Cross over, } \\
\text { sham } \\
\text { controlled }\end{array}$ & 10 & $75 \pm 7$ & $\begin{array}{l}\text { DSM-IV, } \\
\text { NINCDS- } \\
\text { ADRADA }\end{array}$ & $23 \pm 2$ & AchEl & $\begin{array}{l}\text { Anodal/ } \\
\text { cathodal/ } \\
\text { sham, } \\
1.5 \mathrm{~mA} \text {, } \\
15 \mathrm{~min}\end{array}$ & Left/right TPC & $\begin{array}{l}\text { Accuracy of the } \\
\text { word-recognition } \\
\text { memory increased after } \\
\text { atDCS }\end{array}$ \\
\hline \multicolumn{10}{|c|}{ FRONTOTEMPORAL DEMENTIA } \\
\hline $\begin{array}{l}\text { Huey et al. } \\
\text { (2007) }\end{array}$ & $\begin{array}{l}\text { Double- } \\
\text { blind, sham } \\
\text { controlled }\end{array}$ & 10 & $61(46-80)$ & $\begin{array}{l}\text { Criteria } \\
\text { Lund/ } \\
\text { Manchester } \\
1994 \\
\text { MDRS }\end{array}$ & $\begin{array}{l}\text { No } \\
\text { data }\end{array}$ & $\begin{array}{l}\mathrm{AChEI}+ \\
\text { memantine }\end{array}$ & $\begin{array}{l}\text { Active/sham, } \\
2 \mathrm{~mA}, 20 \mathrm{~min}\end{array}$ & $\mathrm{FC}$ & $\begin{array}{l}\text { No improvement in } \\
\text { verbal fluency after } \\
\text { active tDCS }\end{array}$ \\
\hline
\end{tabular}

AChEl, acetylcholine esterase inhibitors; Adas-Cog, Alzheimer's disease assessment scale-cognitive sub scale; ADAS, Alzheimer's disease assessment scale; DLPFC, dorsolateral prefrontal cortex; DSM- IV, Diagnostic and Statistical Manual of Mental Disorders-IV (DSM-IV); FC, frontal cortex; MDRS, Mattis Dementia Rating Scale; MMSE, Mini Mental State Examination; NINCDS-ADRADA, National Institute of Neurological Communicative Disorders and Stroke-Alzheimer disease and Related Disorders Association; TC, temporal cortex; TPC, temporoparietal cortex; VAT, visual attention task; VRT, visual recognition task.

thereof were used as the basis for the Section "tDCS in Demential Disorders."

\section{tDCS IN DEMENTIAL DISORDERS ALZHEIMER'S DISEASE}

The effect of anodal tDCS (atDCS) over the left temporal cortex (TC) and dorsolateral prefrontal cortex (DLPFC) was investigated on recognition and working memory (WM) in $10 \mathrm{AD}$ patients (Boggio et al., 2009), revealing enhancement in a visual recognition memory task after atDCS of the DLPFC and left TC (Boggio et al., 2009). In another study, an improvement in a word-recognition memory in 10 patients with probable $\mathrm{AD}$ was proven after atDCS of the temporoparietal areas (Ferrucci et al., 2008a). In contrast, cathodal tDCS (ctDCS) lead to decreased word-recognition memory. The effect of atDCS persisted up to $30 \mathrm{~min}$ after stimulation, indicating a long-lasting increase in brain excitability (Ferrucci et al., 2008a). Long-term enhancement of visual recognition memory for up to 4 weeks after therapy was found after atDCS in 15 AD patients (Boggio et al., 2011).

\section{FRONTOTEMPORAL DEMENTIA}

A study demonstrated that active tDCS does not result in a beneficial effect in verbal fluency in 10 patients with frontotemporal dementia presenting mainly behavioral (and in one patient language) symptoms (Huey et al., 2007). The lack of effect may be due to the small current that reaches the frontal cortex due to brain atrophy and neuronal loss with concomitant incapability of the affected cortex to respond to brain polarization (Huey et al., 2007).

\section{SAFETY AND SIDE EFFECTS OF tDCS} General observations

There is evidence that tDCS applied to the scalp over the prefrontal cortex over $20 \mathrm{~min}$ does not alter local and global cortical function (Iyer et al., 2005). The current intensity of $1 \mathrm{~mA}$ did not result in significant effects on cortical function, whereas verbal fluency increased with $2 \mathrm{~mA}$-atDCS and decreased with $2 \mathrm{~mA}$ ctDCS (Iyer et al., 2005). In a systematic review, itching, tingling, headache, burning sensation, and discomfort were the most often reported adverse effects of active tDCS vs. sham tDCS (Brunoni et al., 2011). Skin irritation and skin burning can occur after tDCS application due to the electrochemical products' skin contact generated by the direct current (Durand et al., 2002; Palm et al., 2008). In addition, magnetic resonance spectroscopy (MRS) in normal subjects failed to detect changes in acetylaspartate, thus showing that atDCS induced no neurotoxic effects (Rango et al., 2008). Furthermore, in motor cortical areas, tDCS induced no relevant changes in serum neuron-specific enolase, a neuronal damage marker, indicating that tDCS induced no harmful effects (Nitsche et al., 2003).

\section{Observations in AD}

In studies of $\mathrm{tDCS}$ in $\mathrm{AD}$, no adverse effects from $\mathrm{tDCS}$ application were noted (Boggio et al., 2009). Only an itching sensation, but no side effects were reported in the study of $10 \mathrm{AD}$ patients (Ferrucci et al., 2008a). No adverse effects, nor tDCS effects on the Mini Mental State Examination (MMSE), Alzheimer's Disease Assessment Scale-Cognitive sub scale (Adas-Cog), or visual attention task (VAT) scores were observed (Boggio et al., 2011). 
Table 2 | Studies of tDCS on cognitive functions.




Table 2 | Continued

\begin{tabular}{|c|c|c|c|c|c|c|}
\hline Study & $\begin{array}{l}\text { Healthy subjects/ } \\
\text { age (age: mean } \\
\text { [ } \pm \text { standard deviation] } \\
\text { or range) }\end{array}$ & $\begin{array}{l}\text { Stimulation } \\
\text { electrode }\end{array}$ & Polarity & $\begin{array}{l}\text { Duration/ } \\
\text { intensity }\end{array}$ & $\begin{array}{l}\text { Side } \\
\text { effects }\end{array}$ & Effects \\
\hline $\begin{array}{l}\text { Zaehle et al. } \\
\text { (2011) }\end{array}$ & $10,25 \pm 2$ years & Left DLPFC & Anodal/cathodal & $15 \mathrm{~min}, 1 \mathrm{~mA}$ & No & $\begin{array}{l}\text { Increase in WM performance } \\
\text { and amplified oscillatory } \\
\text { power in theta and alpha } \\
\text { bands after atDCS, } \\
\text { interference with WM } \\
\text { performance after ctDCS }\end{array}$ \\
\hline
\end{tabular}

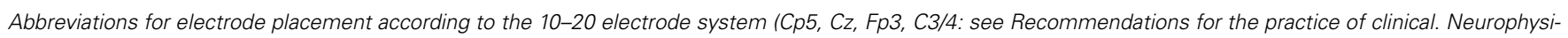

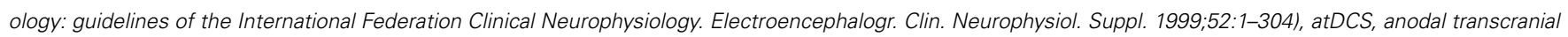
direct current stimulation; min, minutes, ctDCS, cathodal transcranial direct current stimulation, DLPFC, dorsolateral prefrontal cortex; mA, milli Ampere; min, minutes, PD, Parkinson's disease; TPC, temporoparietal cortex.

\section{tDCS IN LEARNING AND MEMORY OBJECT-LOCATION LEARNING IN THE ELDERLY}

The ability to memorize the location of objects is known to worsen by aging and in neurodegenerative dementia. atDCS over the temporoparietal cortex in 20 elderly healthy subjects resulted in improved retention of object-location learning for up to 1 week after learning (Flöel et al., 2011). This finding has relevance concerning memory deficits in normal and pathological aging.

\section{ENHANCING DECLARATIVE MEMORY BY tDCS}

Anodal tDCS enhances slow oscillatory EEG activity that in turn can enhance declarative memories (Marshall et al., 2004). As shown in 32 human healthy subjects, declarative memory can be improved by anodal and impaired by ctDCS of the DLPFC (Javadi and Walsh, 2011).

\section{ENHANCING IMPLICIT MEMORY BY tDCS}

Both declarative and implicit memory are known to improve via tDCS. For instance, atDCS of Broca's area enhanced implicit learning of an artificial grammar in 38 healthy subjects (de Vries et al., 2011), an interesting finding supporting tDCS as a potential instrument in the rehabilitation of aphasic patients.

\section{MODULATION OF WM BY tDCS ENHANCING WM BY tDCS}

Several studies address the physiological effects of tDCS in the WM as a part of declarative memory playing a pivotal role in long-term memory, language, and executive function (Baddeley, 1992).

In 10 patients with cognitive defects after a first-ever stroke, atDCS of the DLPFC led to enhanced WM performance (Jo et al., 2009). In a neurodegenerative disease like Parkinson's, atDCS of the left DLPFC was also shown to improve WM in 18 patients (Boggio et al., 2006). atDCS to the DLPFC lead to WM enhancement in healthy subjects (Fregni et al., 2005; Andrews et al., 2011) and rats, frontal ctDCS enhanced visual-spatial WM (Dockery et al., 2011). Interestingly, atDCS led to amplified oscillation in theta and alpha electroencephalography (EEG) bands and increased WM performance in humans (Zaehle et al., 2011). WM representations are supported by oscillatory brain activity (Lisman and Idiart, 1995). In particular, theta EEG band activity has been associated with memory encoding and retrieval (Jensen and Tesche, 2002). Thus amplified theta band activity is related to WM's executive function, indicating the continuous information processing required during WM performance.

As neuroimaging studies revealed a widespread effect in cortical activity by tDCS (Lang et al., 2005), it is likely to imply a tDCS influence on the entire WM system, and not only on the DLPFC. Furthermore, there is some evidence that WM performance can be improved in a manner dependent on current strength in 14 healthy subjects (Teo et al., 2011). No current strength or time-course effect was observed in the accuracy of WM tasks. However, a significant current by time interaction was found in a WM task (Teo et al., 2011). However, the effectdependence on current intensity of tDCS in memory function is not proven by this single study of one WM task; it requires further examination in healthy subjects and those with diverse cognitive functions.

A time-dependent enhancement of verbal memory resulted after atDCS of the DLPFC (Ohn et al., 2008). Name recall can benefit from atDCS of the anterior temporal lobes (Ross et al., 2011), and word retrieval improved in healthy and non-fluent aphasic patients after atDCS (Fiori et al., 2011).

\section{IMPAIRMENT OF WM AFTER tDCS}

Bilateral prefrontal ctDCS and atDCS during a memory task can impair neuronal processes related to a WM paradigm (Marshall et al., 2005). Furthermore, cerebellar tDCS of both polarities impaired use-dependent improvement in a WM task (Ferrucci et al., 2008b). WM also revealed impairment by ctDCS to the right parietal lobe (Berryhill et al., 2010).

\section{POTENTIAL MECHANISIMS OF ACTION OF tDCS IN AD EFFECTS OF tDCS ON NEURONAL ACTIVITY BY ALTERING THE MEMBRANE POTENTIAL}

In an $\mathrm{AD}$ mouse model, $\mathrm{B}$-amyloid peptide was shown to disturb the resting membrane potential in muscle fibers (Mukhamediarov et al., 2011). Furthermore, B-amyloid 1-42 peptide caused membrane depolarization leading to hyperexcitability of affected neurons in a human neuronal cell model of AD (Blanchard et al., 2002). 
atDCS might be an instrument to alter the neuronal depolarization frequently altered in $\mathrm{AD}$ according to in vitro studies, as atDCS leads to the increased cortical excitability promoting neuronal depolarization (Nitsche and Paulus, 2000). Increasing cortical excitability is a relevant tool in $\mathrm{AD}$, as $\mathrm{AD}$ patients reveal temporoparietal hypoactivity (as characterized by focal slow wave activity in magnetoencephalography; Fernandez et al., 2002).

Motor cortex (Di Lazzaro et al., 2004) and global cortical hyperexcitability is found in AD (Rossini et al., 2007), correlating with cognitive severity in a TMS study (Alagona et al., 2001). As ctDCS led to reduced cortical excitability caused by neuronal hyperpolarization (Nitsche and Paulus, 2000), it might also be beneficial in $\mathrm{AD}$ by lowering its somewhat increased cortical excitability.

Non-synaptic mechanisms based on changes in the membrane potential underlying the after-effects of atDCS and ctDCS (Ardolino et al., 2005) might be responsible for modulating cognitive function in $\mathrm{AD}$. The local changes in ionic concentrations could be due to alterations in transmembrane proteins and from changes in $\mathrm{H}+$ ions induced by exposure to a constant electrical field (Ardolino et al., 2005).

\section{SYNAPTIC AFTER-EFFECTS OF tDCS}

\section{NMDA receptor-dependent after-effects}

tDCS induces prolonged after-effects sharing similarities with long-term potentiation (LTP)- and long-term depression (LTD)like changes in cortical excitability (Paulus, 2004). In an in vitro and in vivo $\mathrm{AD}$ mouse model, LTP as the putative mechanism of learning and memory is evidently impaired by $B$-amyloid peptide (Gengler et al., 2010; Middei et al., 2010). ß-amyloid peptide disruption of LTP is $N$-methyl-D-aspartate (NMDA) receptordependent in the mouse hippocampus in vivo and in vitro (Yamin, 2009).

tDCS-induced after-effects are partly NMDA receptordependent (Liebetanz et al., 2002), suggesting that tDCS aftereffects may alter NMDA receptor-dependent cortical plasticity that may be disturbed in $\mathrm{AD}$.

\section{GABAergic interneurons}

Anodal after-effects are probably mediated in part by gammaaminobutyric acid $(\mathrm{GABA})_{\mathrm{A}}$ ergic interneurons as a reduction in short-interval intracortical inhibition and an increase in I-wave facilitation after tDCS intracortical facilitation (Nitsche et al., 2005; Stagg et al., 2009; Stagg and Nitsche, 2011). As in AD, GABAergic cortical inhibitory interneurons play a role in the disease's early stage (Koliatsos et al., 2006); modulation of these interneurons by tDCS is a possible disease-modifying mechanism. Hippocampus changes in GABA B receptor protein were found in 16 elderly subjects with $\mathrm{AD}$, indicating alterations between the excitatory and inhibitory neurotransmitter systems with consecutively dysfunctional hippocampal circuitry (Iwakiri et al., 2005). A MRS study provides evidence that atDCS causes reduced GABA concentration within the stimulated cortex, whereas ctDCS leads to impaired glutamatergic neuronal activity with a correlated reduction in GABA concentration due to a relationship between these two neurotransmitters (Stagg et al., 2009). Thus tDCS might reduce the disequilibrium between excitatory and inhibitory neurotransmitters systems in AD.

\section{Glutamatergic synapses}

In $\mathrm{AD}$, glutamate receptors may be dysregulated by $\mathrm{B}$-amyloid accumulation resulting in the disrupted glutamatergic activity that coincides with cognitive decline (Parameshwaran et al., 2008). The dysregulation of glutamatergic activity might be altered by atDCS, as there is evidence that glutamatergic synapses are involved in anodal after-effects (Stagg et al., 2009; Stagg and Nitsche, 2011), and MRS data support that glutamate and glutamine levels were elevated in the parietal cortex after atDCS (Clark et al., 2011).

Therefore, ctDCS may have the potential to affect cognitive functions in $\mathrm{AD}$ by modulating glutamatergic synapses.

\section{EFFECTS OF tDCS ON HUMAN REGIONAL CEREBRAL BLOOD FLOW}

There is evidence in $\mathrm{AD}$ that characteristics of the cerebral microvasculature have changed, leading to altered cerebral blood flow (CBF; van Beek et al., 2012). atDCS induced an increase in regional cerebral blood flow ( $\mathrm{rCBF}$ ), whereas ctDCS resulted in a decrease in rCBF during and after stimulation (Zheng et al., 2011). As tDCS modulates CBF in many cortical and subcortical regions with sustained and widespread changes in neuronal activity (Lang et al., 2005), it is an auspicious instrument in AD.

\section{MODULATING OSCILLATORY BRAIN ACTIVITY AND FUNCTIONAL CONNECTIVITY PATTERN VIA tDCS}

$\mathrm{AD}$ led to an altered temporal correlation in parietal and prefrontal oscillations (Montez et al., 2009), more severe deceleration of spontaneous oscillatory activity (Rossini et al., 2007; de Waal et al., 2011), a functional disconnection (Gili et al., 2011), in particular between the prefrontal cortex and hippocampus in AD (Grady et al., 2001), and network connectivity changes (Zhou et al., 2010). It therefore makes sense to use tDCS as a therapeutic tool in $\mathrm{AD}$, as it can reconfigure cerebral networks (Peña-Gómez et al., 2011) and cause changes in functional cerebral connectivity patterns suggesting alterations in brain synchronization (Polanía et al., 2011). As the cognitive dysfunction in brain diseases like $\mathrm{AD}$ is based on abnormal neural synchronization (Polanía et al., 2011), it may be beneficial to cause changes in brain synchronization via tDCS.

More specifically, atDCS over the primary motor cortex combined with inhibitory ctDCS of the contralateral frontopolar cortex caused an increased functional connectivity pattern within the premotor, motor, and sensorimotor areas of stimulated hemispheres in 10 healthy human subjects. Furthermore, intra- and interhemispheric connectivity changes became apparent after atDCS, indicating changes in brain topological functional organization (Uhlhaas and Singer, 2006). Another study demonstrated that ctDCS decreased while atDCS augmented normalized beta and gamma frequency EEG bands, suggesting transient reorganization of cortical activity (Antal et al., 2004). As gamma activity is also part of high-level information processing, it is an adjuvant method to influence higher-order cognitive function (Antal et al., 2004).

\section{MODULATING CORTICAL NEUROTRANSMITTERS VIA tDCS}

Neuronal loss implicates the impairment of serotonergic neuromodulation as a basic mechanism of promoting dementia in AD (Yang et al., 1999). Furthermore, there is dopaminergic modulation of LTD-like plasticity in AD (Koch et al., 2011). Cholinergic systems with ascending projections are also degenerated in 
neurodegenerative dementia (Schmitt, 2005; Fregni et al., 2006). Modulating these neurotransmitter systems via tDCS would therefore seem to be a mechanism-based treatment of AD. Dopaminergic (Nitsche et al., 2006), serotonergic (Nitsche et al., 2009) and cholinergic (Kuo et al., 2007) neuromodulations have been demonstrated by atDCS and ctDCS (Stagg and Nitsche, 2011), indicating another disease-modifying treatment option of tDCS.

There are other mechanisms that determine the response of humans to $\mathrm{tDCS}$, i.e., the BDNF polymorphism (Antal et al., 2004). BDNF modulation is an interesting target in $\mathrm{AD}$, as $\mathrm{B}$ amyloid processing is involved in the BDNF pathway and (Forero et al., 2006) the BDNF ValMet 66 polymorphism is a neural risk for $\mathrm{AD}$ (Voineskos et al., 2011), suggesting BDNF as a factor shaping the cortical excitability response to tDCS in $\mathrm{AD}$ patients.

\section{LIMITATIONS OF CURRENT KNOWLEDGE OF tDCS IN DEMENTIAL DISORDERS}

There are few studies on the effects of tDCS in demential disorders (AD and frontotemporal dementia, see Table 1). The efficacy of tDCS in other demential disorders (for instance vascular dementia or Lewy body dementia) has thus not yet been proven. Furthermore, only a small battery of cognitive functions, i.e., selective attention, WM, visual and word-recognition memory, instruction remembering and word recall has been evaluated so far (see tDCS in Demential Disorders). tDCS effects on other cognitive functions like calculating, cognitive flexibility, language, orientation, short- and long-term memory, and writing will have to be evaluated in studies with larger cohorts and longer control periods. The tDCS effects studied thus far are short-lived (maximum up to 1 month; Boggio et al., 2011) and there are no observations regarding longer-duration interventions. Nor have the long-term side effects of tDCS been assessed. This is particularly important, as

\section{REFERENCES}

Alagona, G., Bella, R., Ferri, R., Carnemolla, A., Pappalardo, A., Costanzo, E., and Pennisi, G. (2001). Transcranial magnetic stimulation in Alzheimer disease: motor cortex excitability and cognitive severity. Neurosci. Lett. 13, 57-60.

Andrews, S. C., Hoy, K. E., Enticott, P. G., Daskalakis, Z. J., and Fitzgerald, P. B. (2011). Improving working memory: the effect of combining cognitive activity and anodal transcranial direct current stimulation to the left dorsolateral prefrontal cortex. Brain Stimul. 4, 84-89.

Antal, A., Varga, E. T., Kincses, T. Z., Nitsche, M. A., and Paulus, W. (2004). Oscillatory brain activity and transcranial direct current stimulation in humans. Neuroreport 15, 1307-1310.

Ardolino, G., Bossi, B., Barbieri, S., and Priori, A. (2005). Non-synaptic mechanisms underlie the aftereffects of cathodal transcutaneous

tDCS applied over longer periods might interact with mechanisms involved in neurodegeneration with either beneficial (delayed deterioration of cognition) or harmful effects (accelerated cognitive deterioration). The interaction of tDCS with pharmacological treatment has not yet been addressed systematically in studies. However, current data indicate there is no significant interaction between medication outcome and its interaction with tDCS (Boggio et al., 2011).

\section{PERSPECTIVES OF tDCS IN AD}

tDCS may enhance our understanding of the neurobiological substrates underlying the cognitive decline in AD. Factors such as cognitive reserve, genetic variants, learning capacity, volumetric studies of cortical thinning and white matter volume, and integrity will have to be thoroughly and systematically investigated in future studies of tDCS on cortical functions in AD. The therapeutic efficacy of tDCS must be examined by outcome scales commonly used in trials of pharmacological agents such as the ADAS-Cog (Freitas et al., 2011). Moreover, multiple target $\mathrm{tDCS}$ or tDCS targeting new brain areas must be developed to overcome multiple cognitive deficits in $\mathrm{AD}$. A multi-electrode stimulation set-up was recently demonstrated that increased focalty and intensity at the brain target (Dmochowksi et al., 2011).

\section{CONCLUSIONS}

tDCS is an easy to perform and non-invasive alternative therapeutic tool for neurodegenerative diseases such as $\mathrm{AD}$. Its effects comprise the enhancement of cognitive functions in explicit and implicit memory. The mechanisms of tDCS are based on changes in membrane polarization, cerebral blood flow, functional connectivity, and brain oscillatory activity that may be altered in $\mathrm{AD}$ and other demential disorders.

current stimulation in Alzheimer's disease. Brain Stimul. [Epub ahead of print].

Boggio, P. S., Ferrucci, R., Rigonatti, S. P., Covre, P., Nitsche, M., PascualLeone, A., and Fregni, F. (2006). Effects of transcranial direct current stimulation on working memory in patients with Parkinson's disease. J. Neurol. Sci. 249, 31-38.

Boggio, P. S., Khoury, L. P., Martins, D. C., Martins, O. E., de Macedo, E. C., and Fregni, F. (2009). Temporal cortex direct current stimulation enhances performance on a visual recognition memory task in Alzheimer disease. $J$. Neurol. Neurosurg. Psychiatr. 80, 444-447.

Brunoni, A. R., Amadera, J., Berbel, B., Volz, M. S., Rizzerio, B. G., and Fregni, F. (2011). A systematic review on reporting and assessment of adverse effects associated with transcranial direct current stimulation. Int. J. Neuropsychopharmacol. 14, 1133-1145.
Clark, V. P., Coffman, B. A., Trumbo, M. C., and Gasparovic, C. (2011). Transcranial direct current stimulation (tDCS) produces localized and specific alterations in neurochemistry: a $1 \mathrm{H}$ magnetic resonance spectroscopy study. Neurosci. Lett. 500, 67-71.

Creutzfeld, O. D., Fromm, G. H., and Kapp, H. (1962). Influence of transcortical d-c currents on cortical neuronal activity. Exp. Neurol. 5, 436-452.

de Vries, M. H., Barth, A. C., Maiworm, S., Knecht, S., Zwiserlood, O., and Flöel, A. (2011). Electrical stimulation of Broca's area enhances implicit learning of an artificial grammar. J. Cogn. Neurosci. 22, 2427-2436.

de Waal, H., Stam, C. J., de Haan, W., van Straaten, E. C., Scheltens, P., and van der Flier, W. M. (2011). Young Alzheimer patients show distinct regional changes of oscillatory brain dynamics. Neurobiol. Aging 33, 1008: e25-e31. 
Di Lazzaro, V., Oliviero, A., Pilato, F., Saturno, O., Dileone, M., Marra, C., Daniele, A., Ghirlanda, S., Gainotti, G., and Tonalli, P. A. (2004). Motor cortex hyperexcitability to transcranial magnetic stimulation in Alzheimer's disease. J. Neurol. Neurosurg. Psychiatr. 75, 555-559.

Dmochowksi, J. P., Datta, A., Bikson, M., Su, Y., and Parra, L. C. (2011). Optimized multi-electrode stimulation increases focalty and intensity at target. J. Neural Eng. 8, 046011.

Dockery, C. A., Liebetanz, D., Birbaumer, N., Malinowska, M., and Wesierska, M. J. (2011). Cumulative benefits of frontal transcranial direct current stimulation on visuospatial working memory training and skill learning in rats. Neurobiol. Learn. Mem. 96, 452-460.

Durand, S., Fromy, B., Bouyé, P., Saumet, J. L., and Abraham, P. (2002).Vasodilatation in response to repeated anodal current application in the human skin relies on aspirinsensitive mechanisms. J. Physiol. (Lond.) 540, 261-269.

Fernandez, A., Maestu, F., Arno, C., Gil, P., Fehr, T., Wienbruch, C., Rockstroh, B., Elbert, T., and Ortiz, T. (2002). Focal temporoparietal slow activity in Alzheimer's disease revealed by magnetoencephalography. Biol. Psychiatry 52, 764-770.

Ferrucci, R., Mameli, F., Guidi, I., Mrakic-Sposta, S., Vergari, M., Marceglia, S., Cogiamanian, F., Barbieri, S., Scarpini, E., and Priori, A. (2008a). Transcranial direct current stimulation improves recognition memory in Alzheimer disease. Neurology 71, 493-498.

Ferrucci, R., Marceglia, S., Vergari, M., Cogiamanian, F., Mrakic-Sposta, S., Mameli, F., Zago, S., Barbieri, S., and Priori, A. (2008b). Cerebellar transcranial direct current stimulation impairs the practicedependent proficiency increase in working memory. J. Cogn. Neurosci. 20, 1687-1697.

Fiori, V., Coccia, M., Marinelli, C. V., Vecchi, V., Bonifazi, S., Ceravolo, M. G., Provinviali, L., Tomaiuolo, F., and Marangolo, P. (2011). Transcranial direct current stimulation improves word retrieval in healthy and nonfluent aphasic subjects. J. Cogn. Neurosci. 23, 2309-2323.

Flöel, A., Rösser, N., Michka, O., Knecht, S., and Breitenstein, C. (2008). Noninvasive brain stimulation improves language learning. J. Cogn. Neurosci. 20, 1415-1422.

Flöel, A., Suttorp, W., Kohl, O., Kürten, J., Lohmann, H., Breitenstein, C., and Knecht, S. (2011). Non-invasive brain stimulation improves objectlocation learning in the elderly. $\mathrm{Neu}$ robiol. Aging [Epub ahead of print].

Forero, D. A., Cascadesus, G., Perry, G., and Arboleda, H. (2006). Synaptic dysfunction and oxidative stress in Alzheimer's disease: emerging mechanisms. J. Cell. Mol. Med. 10, 796-805.

Fregni, F., Boggio, P. S., Nitsche, M., Bermpohl, F., Antal, A., Feredoes, F., Marcolin, M. A., Rigonatti, S. P., Silva, M. T., Paulus, W., and PascualLeone, A. (2005). Anodal transcranial direct current stimulation of prefrontal cortex enchances working memory. Exp. Brain Res. 166, 23-30.

Fregni, F., Boggio, P. S., Nitsche, M. A., Marcolin, M. A., Rigonatti, S. P., and Pascual-Leone, A. (2006). Treatment of major depression with transcranial direct current stimulation. Bipolar Disord. 8, 203-204.

Freitas, C., Mondragón-Llorca, H., and Pascual-Leone, A. (2011). Noninvasive brain stimulation in Alzheimer's disease: systematic review and perspectives for the future. Exp. Gerontol. 46, 611-627.

Gengler, S., Hamilton, A., and Hölscher, C. (2010). Synaptic plasticity in the hippocampus of a APP/PS 1 mouse model of Alzheimer's disease is impaired in old but not young mice. PLoS ONE 5, e9764. doi:10.1371/journal.pone.0009764

Gili, T., Cercignani, M., Serra, L., Perri, R., Giove, F., Maraviglia, B., Caltagirone, C., and Bozzali, M. (2011). Regional brain atrophy and functional disconnection across Alzheimer's disease evolution. J. Neurol. Neurosurg. Psychiatr. 82, 58-66.

Grady, C. L., Furey, M. L., Pietrini, P., Horwitz, B., and Rapoport, S. I. (2001). Altered brain functional connectivity and impaired shortterm memory in Alzheimer's disease. Brain 124, 739-756.

Huey, C. D., Probasco, J. C., Moll, J., Stocking, J., Ko, M. H., and Wassermann, E. M. (2007). No effect of DC brain polarization on verbal fluency in patients with advanced frontotemporal dementia. Clin. Neurophysiol. 118, 1417-1418.

Iwakiri, M., Mizukami, K., Ikonomovic, M. D., Ishikawa, M., Hidaka, S., Abrahamson, E. E., DeKosky, S. T., and Asada, T. (2005). Changes in hippocampal GABABR1 subunit expression in Alzheimer's patients: association with Braak staging. Acta Neuropathol. 109, 467-474.

Iyer, M. B., Mattu, U., Grafman, J., Lomarev, M., Sato, S., and Wassermann, E. M. (2005). Safety and cognitive effect of frontal DC brain polarization in healthy individuals. Neurology 64, 872-875.

Javadi,A. H., and Walsh, V. (2011). Transcranial direct current stimulation (tDCS) of the left dorsolateral prefrontal cortex modulates declarative memory. Brain Stimul. [Epub ahead of print].

Jensen, O., and Tesche, C. D. (2002). Frontal theta activity in humans increases with memory load in a working memory task. Eur. J. Neurosci. 15, 1395-1399.

Jo, J. M., Kim, Y., Ohn, S. H., Joen, B., and Lee, K. H. (2009). Enhancing the working memory of stroke patients using tDCS. Am. J. Phys. Med. Rehabil. 88, 404-409.

Kincses, T. Z., Antal, A., Nitsche, M. A. Bártfai, O., and Paulus, W. (2004). Facilitation of probabilistic classification learning by transcranial direct current stimulation of the prefrontal cortex in the human. Neuropsychologia 42, 113-117.

Koch, G., Esposito, Z., Codecà, C., Mori, F., Kusayanagi, H., Monteleone, F., Di Lorenzo, F., Bernardi, G., and Martorana, A. (2011). Altered dopamine modulation of LTD-like plasticity in Alzheimer's disease patients. Clin. Neurophysiol. 122, 703-707.

Koliatsos, V. E., Kecojevic, A., Troncoso, J. C., Gastard, M. C., Bennett, D. A., and Schneider, J. A. (2006). Early involvement of small inhibitory cortical interneurons in Alzheimer's disease. Acta Neuropathol. 112, 147-162.

Kuo, M. F., Grosch, J., Fregni, F., Paulus, W., and Nitsche, M. A. (2007). Focusing effect of acetylcholine on neuroplasticity in the human motor cortex. J. Neurosci. 27, 14442-14447.

Lang, N., Siebner, H. R., Ward, N. S., Lee, L., Nitsche, M. A., Paulus, W., Rothwell, J. C., Lemon, R. N., and Frackowiak, R. S. (2005). How does transcranial DC stimulation of the primary motor cortex alter regional neuronal activity in the human brain? Eur. J. Neurosci. 22, 495.

Liebetanz, D., Nitsche, M. A., Tergau, F., and Paulus, W. (2002). Pharmacological approach to the mechanisms of transcranial DCstimulation-induced after-effects of human motor cortex excitability. Brain 125, 2238-2247.

Lisman, J. E., and Idiart, M. A. (1995). Storage of $7 \pm 2$ short term memories in oscillatory subcycles. Science 267, 1512-1515

Marshall, L., Mölle, M., Hallschmidt, M., and Born, J. (2004). Transcranial direct current stimulation during sleep improves declarative memory. J. Neurosci. 3, 9985-9992.

Marshall, L., Mölle, M., Siebner, H. R., and Born, J. (2005). Bifrontal transcranial direct current stimulation slows reaction time in a working memory task. BMC Neurosci. 8, 23. doi:10.1186/1471-2202-6-23

Middei, S., Roberto, A., Berretta, N., Panico, M. B., Lista, S., Bernardi, G., Mercuri, N. B., Ammassari-Teule, M., and Nistico, R. (2010). Learning discloses abnormal structural and functional plasticity at hippocampal synapses in the APP23 mouse model of Alzheimer's disease. Learn. Mem. 19, 236-240.

Montez, T., Poil, S. S., Jones, B. F., Manshanden, I., Verbunt, J. P., van Dijk, B. W., Brussaard, A. B., van Ooyen, A., Stam, C. J., Scheltens, P., and Linkenkaer-Hansen, K. (2009). Altered temporal correlations in parietal alpha and prefrontal theta oscillations in early-stage Alzheimer disease. Proc. Natl. Acad. Sci. U.S.A. 106, 1614-1619.

Monti, A., Cogiamanian, F., Marceglia, S., Ferrucci, R., Mameli, F., MrakicSposta, S., Vergari, M., Zago, S., and Priori, A. (2008). Improved naming after transcranial direct current stimulation in aphasia. J. Neurol. Neurosurg. Psychiatr. 79, 451-453.

Mukhamediarov, M. A., Volkov, E. M., Leushina, A. V., Kochunova, I. U. O., Palotas, A., and Zefirov, A. L. (2011). Ionic and molecular mechanisms of beta-amyloid-induced depolarization of the mouse skeletal muscle fibres. Ross. Fiziol. Zh. Im. I M Sechenova 97, 795-803.

Nitsche, M. A., Kuo, M. F., Karrasch, R., Wächter, B., Liebetanz, D., and Paulus, W. (2009). Serotonin affects transcranial direct current-induced neuroplasticity in humans. Biol. Psychiatry 66, 503-508.

Nitsche, M. A., Lampe, C., Antal, A., Liebetanz, D., Lang, N., Tergau, F., and Paulus, W. (2006). Dopaminergic modulation of long-lasting direct current-induced cortical excitability changes in the human motor cortex. Eur. J. Neurosci. 23, 1651-1657.

Nitsche, M. A., Nitsche, M. S., Klein, C. C., Tergau, F., Rothwell, J. C., and Paulus, W. (2003). Level of action of cathodal DC polarisation induced inhibition of the human motor cortex. Clin. Neurophysiol. 114, 600-604.

Nitsche, M. A., and Paulus, W. (2000). Excitability changes induced in the human motor cortex by weak transcranial direct current stimulation. J. Physiol. (Lond.) 527, 633-639. 
Nitsche, M. A., Seeber, A., Frommann, K., Klein, C. C., Rochford, C., Nitsche, M. S., Fricke, K., Liebe$\operatorname{tanz}$, D., Lang, N., Antal, A., Paulus, W., and Tergau, F. (2005). Modulating parameters of excitability during and after transcranial direct current stimulation of the human motor cortex. J. Physiol. (Lond.) 568, 291-303.

Ohn, S. H., Park, C. I., Yoo, W. K., Ko, M. H., Choi, K. P., Kim, G. M., Lee, Y. T., and Kim, Y. H. (2008). Time-dependent effect of transcranial direct current stimulation on the enhancement of working memory. Neuroreport 8 , 43-47.

Palm, U., Keeser, D., Schiller, C., Fintescu, Z., Nitsche, M., Reisinger, E., and Padberg, F. (2008). Skin lesions after treatment with transcranial direct current stimulation (tDCS). Brain Stimul. 1, 386-387.

Parameshwaran, K., Dhanasekaran, M., and Suppiramaniam, V. (2008). Amyloid beta peptides and glutamatergic synaptic dysregulation. Exp. Neurol. 210, 7-13.

Paulus, W. (2004). Outlasting excitability shifts induced by direct current stimulation of the human brain. Suppl. Clin. Neurophysiol. 57, 708-714.

Peña-Gómez, C., Sala-Lonch, R., Junqué, C., Clemente, I. C., Vidal, D., Bargalló, N., Falcón, C., Valls-Solé, J., Pascual-Leone, A., and BartrésFaz, D. (2011). Modulation of largescale brain networks by transcranial direct current stimulation evidenced by resting-state functional MRI. Brain Stimul. [Epub ahead of print].

Penolazzi, B., Di Domenico, A., Marzoli, D., Mammarella, N., Fairfield, B., Franciotti, R., Brancucci, A., and Tommasi, L. (2010). Effects of Transcranial Direct Current Stimulation on episodic memory related to emotional visual stimuli. PLoS ONE 5, e10623. doi:10.1371/journal.pone. 0010623
Polanía, R., Nitsche, M. A., and Paulus, W. (2011). Modulating functional connectivity patterns and topological functional organization of the human brain with transcranial direct current stimulation. Hum. Brain Mapp. 32, 1236-1249.

Purpura, D. P., and McMurtry, J. G. (1965). Intracellular activities and evoked potential changes during polarization of motor cortex. J. Neurophysiol. 171, 1-25.

Rango, M., Cogiamanian, F., Marceglia, S., Barberis, B., Arighi, A., Biondetti, P., and Priori, A. (2008). Myoinositol content in the human brain is modified by transcranial direct current stimulation in a matter of minutes: a 1H-MRS study. Magn. Reson. Med. 60, 782-789.

Ross, L. A., McCoy, D., Coslett, H. B., Olson, I. R., and Wolk, D. A. (2011). Improved proper name recall in aging after electrical stimulation of the anterior temporal lobes. Front. Aging Neurosci. 3:6. doi:10.3389/fnagi.2011.00016

Rossini, P. M., Rossi, S., Babiloni, C., and Polich, J. (2007). Clinical neurophysiology of aging brain: from normal aging to neurodegeneration. Prog. Neurobiol. 83, 375-400.

Schliebs, R., and Arendt, T. (2011). The cholinergic system in aging and neuronal degeneration. Behav. Brain Res. 22, 555-563.

Schmitt, H. P. (2005). Neuromodulation, aminergic neurodisinhibition and neurodegeneration. Draft of a comprehensive theory for Alzheimer disease. Med. Hypotheses 65, 1106-1119.

Sparing, R., Dafotakis, M., Meister, I. G., Thirugnanasambandam, N., and Fink, G. R. (2008). Enhancing language performance with noninvasive brain stimulation-a transcranial direct current stimulation study in healthy humans. Neuropsychologia 46, 261-268.

Stagg, C. J., Best, J. G., Stephenson, M. C., O’Shea, J., Wylezinska,
M., Kincses, Z. T., Morris, P. G., Matthews, P. M., and Johansen-Berg, H. (2009). Polarity-sensitive modulation of cortical neurotransmitters by transcranial stimulation. $J$. Neurosci. 29, 5202-5206.

Stagg, C. J., and Nitsche, M. A. (2011). Physiological basis of transcranial direct current stimulation. Neuroscientist 17, 37-53.

Teo, F., Hoy, K. E., Daskalakis, Z. J., and Fitzgerald, P. B. (2011). Investigating the role of current strength in tDCS modulation of working memory performance in healthy controls. Front. Psychiatry 2:45. doi:10.3389/fpsyt.2011.00045

Thies, W., and Bleiler, L. (2011). Alzheimer's disease facts and figures. Alzheimers Dement. 7, 208-244.

Uhlhaas, P. J., and Singer, W. (2006). Neural synchrony in brain disorders: relevance for cognitive dysfunctions and pathophysiology. Neuron 52, 155-168.

van Beek, A. H., Lagro, J., Olde-Rikkert, M. G., Zhang, R., and Claassen, J. A. (2012). Oscillations in cerebral blood flow and cortical oxygenation in Alzheimer's disease. Neurobiol. Aging 33, 428-431.

Voineskos, A. N., Lerch, J. P., Felsky, D., Shaikh, S., Rajji, T. K., Miranda, D., Lobaugh, N. J., Mulsant, B. H., Pollock, B. G., and Kennedy, J. L. (2011). The brain-derived neurotrophic factor Val66Met polymorphism and prediction of neural risk for Alzheimer disease. Arch. Gen. Psychiatry 68, 198-206.

Yamin, G. (2009). NMDA receptordependent signaling pathways that underlie amyloid beta-protein disruption of LTP in the hippocampus. J. Neurosci. Res. 87, 1729-1736.

Yang, Y., Beyreuther, K., and Schmitt, H. P. (1999). Spatial analysis of the neuronal density of aminergic brainstem nuclei in primary neurodegenerative and vascular dementia: a comparative immunocytochemical and quantitative study using a graph method. Anal. Cell. Pathol. 19 , 125-138.

Zaehle, T., Sandmann, P., Thorne, J. D., Jäncke, L., and Herrmann, C. S. (2011). Transcranial direct current stimulation of the prefrontal cortex modulates working memory performance: combined behavioural and electrophysiological evidence. BMC Neurosci. 12, 2. doi:10.1186/1471-2202-12-2

Zheng, X., Alsop, D. C., and Schlaug, G. (2011). Effects of transcranial direct current stimulation (tDCS) on human regional cerebral blood flow. Neuroimage 1, 26-33.

Zhou, J., Greicius, M. D., Gennatas, E. D., Growdon, M. E., Jang, J. Y., Rabinovici, G. D., Kramer, J. H., Weiner, M., Miller, B. L., and Seeley, W. W. (2010). Divergent network connectivity changes in behavioural variant frontotemporal dementia and Alzheimer's disease. Brain 133, 1352-1367.

Conflict of Interest Statement: The author declares that the research was conducted in the absence of any commercial or financial relationships that could be construed as a potential conflict of interest.

Received: 02 March 2012; accepted: 24 April 2012; published online: 15 May 2012.

Citation: Hansen N (2012) Action mechanisms of transcranial direct current stimulation in Alzheimer's disease and memory loss. Front. Psychiatry 3:48. doi: 10.3389/fpsyt.2012.00048

This article was submitted to Frontiers in Neuropsychiatric Imaging and Stimulation, a specialty of Frontiers in Psychiatry. Copyright (c) 2012 Hansen. This is an open-access article distributed under the terms of the Creative Commons Attribution Non Commercial License, which permits non-commercial use, distribution, and reproduction in other forums, provided the original authors and source are credited. 